\title{
Abscisic acid and blue light signaling pathways in chloroplast movements in Arabidopsis mesophyll*
}

\author{
Aleksandra Eckstein ${ }^{\bowtie}$, Weronika Krzeszowiec ${ }^{1}$, Agnieszka Katarzyna Banaś1 , Franciszek \\ Janowiak$^{2}$ and Halina Gabryś $1 \bowtie$ \\ 1 Jagiellonian University, Faculty of Biophysics, Biochemistry and Biotechnology, Department of Plant Biotechnology, Kraków, Poland \\ 2The Franciszek Górski Institute of Plant Physiology of Polish Academy of Sciences, Kraków, Poland
}

\begin{abstract}
Abscisic acid (ABA) and phototropins act antagonistically to control stomatal movements. Here, we investigated the role of $A B A$ in phototropin-directed chloroplast movements in mesophyll cells of Arabidopsis thaliana. We analyzed the expression of phototropins at mRNA and protein level under the influence of ABA. PHOT1 mRNA level was decreased by $A B A$ in the dark while it was insensitive to ABA in light. PHOT2 mRNA level was independent of the hormone treatment. The levels of phototropin proteins were down-regulated by $A B A$, both in darkness and light. No impact of exogenous $A B A$ on amplitudes and kinetics of chloroplast movements was detected. Chloroplast responses in wild type Arabidopsis and three mutants, abi4, abi2 (abscisic acid insensitive4, 2) and aba1 (abscisic acid1), were measured to account for endogenous ABA signaling. The chloroplast responses were slightly reduced in abi2 and $a b a 1$ mutants in strong light. To further investigate the effect, $a b i 2$ and aba1 mutants were supplemented with exogenous ABA. In the aba1 mutant, the reaction was rescued but in abi2 it was unaffected. Our results show that $A B A$ is not directly involved in phototropin-controlled chloroplast responses in mature leaves of Arabidopsis. However, the disturbance of ABA biosynthesis and signaling in mutants affects some elements of the chloroplast movement mechanism. In line with its role as a stress hormone, ABA appears to enhance plant sensitivity to light and promote the chloroplast avoidance response.
\end{abstract}

Key words: abscisic acid, abscisic acid mutants, Arabidopsis thaliana, blue light, chloroplast movement, phototropins

Received: 20 March, 2016; revised: 26 April, 2016; accepted: 29 June, 2016; available on-line: 02 August, 2016

\section{INTRODUCTION}

\section{Blue light-controlled chloroplast movements}

Chloroplast redistribution is a common physiological phenomenon in plant cells (reviewed in Gabryś \& Krzeszowiec, 2012). It can be defined as an intracellular directional movement that depends on the quality and quantity of light. In fact, chloroplasts perform two distinct movement responses, avoidance and accumulation (see Banaś et al., 2012 and ref. therein). These reactions have two known functions. The avoidance response plays a role in the protection of the photosynthetic apparatus in strong light (Kasahara et al., 2002; Sztatelman et al., 2010). In this case chloroplasts avoid cell regions exposed to strong light. They redistribute toward cell walls parallel to light direction and screen each other. The accumulation response plays a role in fine-tuning photosynthesis in weak and intermediate light - chloroplasts accumulate in the most illuminated area of the cell to maximize light absorption (Zurzycki, 1955). Lightinduced chloroplast movements have been discussed in numerous reviews (Haupt \& Scheuerlein, 1990; Haupt, 1999; Takagi, 2003; Wada et al., 2003; Gabryś, 2004; Wada \& Suetsugu, 2004; Gabryś, 2012; Banaś et al., 2012; Gabryś \& Krzeszowiec, 2012).

Chloroplast responses are induced by blue light in most higher plants (Gabryś 2012). The blue light signal is perceived by phototropins, photoreceptors which are light-activated protein kinases. In Arabidopsis thaliana two phototropins have been identified: phot1 and phot2. Both phototropins control the accumulation response, whereas mainly phot 2 directs the avoidance response (Jarillo et al., 2001; Kagawa et al., 2001; Sakai et al., 2001). Apart from chloroplast redistribution they also control other acclimation responses: phototropism (Sakai et al., 2001), leaf flattening (Inoue et al., 2008), nuclear avoidance movement (Iwabuchi et al., 2007) and stomatal opening (Kinoshita et al., 2001). The studies of chloroplast movements in higher plants are currently based on two main models, Arabidopsis thaliana (Trojan \& Gabryś 1996; Oikawa et al., 2003; Suetsugu et al., 2005; Banaś \& Gabryś 2007; Krzeszowiec et al., 2007; Kadota et al., 2009) and Nicotiana tabacum (Nauš et al., 2008; AnielskaMazur et al., 2009; Augustynowicz et al., 2009; Eckstein et al., 2016).

\section{Absicisic acid signaling}

The plant hormone abscisic acid (ABA) plays an important role in the regulation of several developmental processes, from seed maturation to senescence. It is also a key factor in plant responses to environmental conditions, especially water stress. Many of these reponses are dependent on endogenous $\mathrm{ABA}$ levels, which result from the interplay between $\mathrm{ABA}$ biosynthesis, degradation and the formation of inactive conjugates (Nambara \& MarionPoll, 2005). One of the key enzymes in ABA biosynthesis is zexanthin epoxidase encoded by the $A B A 1$ gene in A. thaliana (Marin et al., 1996). It catalyses the conversion of zeaxanthin to violaxanthin and is also involved in the

e-mail: Halina Gabryś e-mail: halina.gabrys@uj.edu.pl; Aleksandra Eckstein e-mail: aleksandra.eckstein@uj.edu.pl

*A preliminary report on the same subject was presented at the 43rd Winter School of the Faculty of Biochemistry, Biophysics and Biotechnology, 16-20 February 2016, Zakopane, Poland.

Abbreviations: ABA, abscisic acid; BL, blue light; DW, dry weight; phot1, phot2, phototropin 1 and 2 
xanthophyll cycle. The aba1 mutant shows reduced growth and significantly lower endogenous ABA content (Rock \& Zeevaart, 1991; Barrero et al., 2005).

Only recently has the PYR/PYL/RCAR-PP2C-SnRK2 (PYRABACTIN RESISTANCE/PYR1-LIKE/REGULATORY COMPONENT OF ABA RECEPTOR - PROTEIN PHOSPHATASE 2C - SUCROSE NON-FERMENTING1-RELATED PROTEIN KINASE 2) ABA signaling pathway been fully elucidated (Ma et al., 2009; Park et al., 2009; Umezawa et al., 2009; Umezawa et al., 2010). The binding of ABA by receptors belonging to the PYR/PYL/RCAR protein family promotes their interaction with type $2 \mathrm{C}$ protein phosphatases (PP2Cs). PP2Cs act as negative regulators of ABA signaling by dephosphorylating and inhibiting SnRK2 kinases. Upon ABA perception PP2C phosphatase activity is inhibited, which allows SnRK2 activation and further signal transduction. In A. thaliana PP2Cs are encoded by $A B I 1$ and $A B I 2(A B A$ INSENSITIVE) genes (Leung et al., 1994; Meyer et al., 1994; Leung et al., 1997; Rodriguez et al., 1998). The abi1 and abi2 mutants exhibit constitutive phosphatase activity and in consequence SnRK2 inactivation, resulting in plant insensitivity to ABA. abi1 and abi2 show reduced sensitivity to exogenous $\mathrm{ABA}$ and incresed $\mathrm{ABA}$ accumulation under low water potential, but normal stomatal behaviour (Korneef et al., 1984; Assmann et al., 2000; Verslues \& Bray, 2006). Recently ABI2 has been shown to participate in ABA-mediated regulation of chloroplast gene transcription (Yamburenko et al., 2015)

Numerous interactions have been identified between $\mathrm{ABA}$ and other signaling pathways, including responses to other hormones, sugars and pathogens (Brady \& McCourt, 2003; Rook et al., 2006; Acharya \& Assmann, 2009; Cao et al., 2011). One of the proteins responsible for ABA cross-talk is ABI4 (ABA INSENSITIVE 4), an AP2/ERF transcription factor (Finkelstein et al., 1998). It participates, among others, in plastid retrograde signaling by regulating nuclear genes for photosynthesis and chlorophyll metabolism, and acts as an integrator of environmental signals (Leon et al., 2013; Wind et al., 2013; Zhang et al., 2013). The abi4 mutant exhibits ABA-insensitive germination but normal seed dormancy and stomatal responses (Finkelstein et al., 1994).

\section{Crosstalk between ABA and phototropins}

A link between the stress hormone ABA and phototropins was first established in stomatal movements. Blue light-controlled opening of the stomatal apparatus starts with the photoexcitation of phototropins. The BLUS1 (BLUE LIGHT SIGNALING1) Ser/Thr protein kinase is a phototropin substrate and a primary regulator of stomatal opening (Takemiya et al., 2013). Subsequently, the signal is transduced to a plasma membrane $\mathrm{H}^{+}$-ATPase which establishes a protonmotive force allowing ion uptake. Mainly $\mathrm{K}^{+}$is transported into the cell via KAT1 and KAT2, two voltagegated $\mathrm{K}^{+}$inward-rectifying channels activated upon hyperpolarization of the plasma membrane (Pilot et al., 2001; Sirichandra et al., 2009). Two more proteins are known to be involved in the signaling pathway: a 143-3 protein (Tseng et al., 2012) and a type 1 protein phosphatase (PP1) (Takemiya et al., 2010). The other key factor regulating guard cell movement is ABA (for review see Sirichandra et al., 2009) which induces stomatal closure. The core signaling module in stomatal closure is the ABA receptor complex PYR/PYL/ RCAR-PP2C-SnRK2 (Ma et al., 2009; Park et al., 2009; Umezawa et al., 2009). ABA blocks the plasma mem- brane $\mathrm{H}^{+}$-ATPase acting via PP1 inhibition (Zhang et al., 2004; Takemiya \& Shimazaki, 2010). Simultaneously, $\mathrm{ABA}$ inhibits the $\mathrm{K}^{+}$influx channel, and activates S-type anion channels. The resulting depolarization of the plasma membrane activates $\mathrm{K}^{+}$efflux from the cell that decreases the turgor of guard cells and causes stomatal closing (for review see Hubbard et al., 2010). The effect of water stress which activates the ABA pathway dominates over light in accordance with the physiological role of stomatal movements. Although $\mathrm{ABA}$ and blue light are the main regulators of guard cell movements, other signaling pathways modulate these responses. In particular, other hormones influence stomatal behaviour (Acharya \& Assmann 2009 and ref. therein). Both auxins and cytokinins promote stomatal opening and inhibit ABA-induced stomatal closure, although opposite effects can sometimes also be observed (Blackman \& Davies, 1983; Lohse \& Hedrich, 1992; Tanaka et al., 2006). Auxin acts by activating the plasma membrane $\mathrm{H}^{+}$-ATPase. Another potent activator of the $\mathrm{H}^{+}$-ATPase and stomatal opening is the fungal phytotoxin fusicoccin (Assmann \& Schwarz, 1992; Kinoshita \& Shimazaki, 2001). Jasmonates, salicylic acid and brassinosteroids usually act as positive regulators of stomatal closure (Mori et al., 2001; Suhita et al., 2003; Haubrick et al., 2006) whereas the effects of ethylene on stomatal aperture are strongly dependent on cross-talk with other hormones (Tanaka et al., 2005; Desikan et al., 2006).

ABA has been shown to influence chloroplast movements in A. thaliana guard cells (Königer et al., 2010). In WT plants the chloroplast arrangement was similar in darkness and low light, with most chloroplasts located in the central position. In high light most chloroplasts relocated towards the pore. After exogenous ABA treatment $(10 \mu \mathrm{M})$ no influence of light on chloroplast distribution was observed. The mechanism underlying this effect remains unknown.

Recently Rojas-Pierce and coworkers (2014) established a link between ABA and chloroplast movements in $A$. thatiana mesophyll cells. This work provides evidence for the involvement of PMI1 (PLASTID MOVEMENT IMPAIRED1), a gene required for normal chloroplast relocations, in two ABA-related responses: regulation of seed germination and $\mathrm{ABA}$ accumulation in seedlings during water deficit. On the other hand the authors have shown the impairment of chloroplast movements in some ABA biosynthesis and signaling mutants. Much earlier, some connections between xanthophyll homeostasis and chloroplast movement have been shown (Tlałka et al., 1999; DeBlasio et al., 2005), but the authors never referred to ABA metabolism in their discussions. Tlałka and others (1999) have shown a correlation between zeaxanthin level and chloroplast responses to strong blue light. DeBlasio and coworkers (2005) have shown impaired avoidance responses in the npq2-1 (nonphotochemical quenching2-1) mutant, also called aba1-6 (abscisic acid1-6), lacking zeaxanthin epoxidase and deficient in ABA biosynthesis. In the light of present findings, these results seem in line with the postulated role of $\mathrm{ABA}$ in chloroplast movements.

The aim of the this study was to elucidate the role of $\mathrm{ABA}$ in the control of chloroplast redistribution in the photosynthetic tissue of $A$. thaliana. In particular, we asked two questions: 1) does $\mathrm{ABA}$ affect the expression of phototropins? 2) what is the nature of the crosstalk between $\mathrm{ABA}$ and phototropin signaling pathways in the control of chloroplast movements in mesophyll tissue? 


\section{MATERIALS AND METHODS}

Plant material. Arabidopsis thaliana wild-type (WT) Columbia seeds (Col-0 N60000) and mutants abi4-1 (abscisic acid insensitive4-1, CS8104), abi2-1 (abscisic acid insensitive2-1, CS23) and aba1-6 (abscisic acid1-6, CS3772) were obtained from Nottingham Arabidopsis Stock Center (Nottingham, UK). Plants were grown in JIFFY-7 pots (Jiffy International AS, Norway) in a growth chamber (Sanyo MLR $350 \mathrm{H}$, Japan) with a 10/14 h light/dark photoperiod at $23^{\circ} \mathrm{C}, 80 \%$ relative humidity, and illumination by fluorescent lamps (FL40SS.W/37, Sanyo) with a photosynthetic photon flux density of $100 \mu \mathrm{mol} \mathrm{m} \mathrm{m}^{-2} \mathrm{~s}^{-1}$. 5 week-old plants were used for all experiments.

ABA treatments. Three types of ABA treatments were applied. (1) The short-term treatment consisted in an infiltration of dark-adapted leaves $1 \mathrm{~h}$ before the induction of chloroplast responses. The infiltration was performed in the dark room under very dim, green safe light. Detached leaves were infiltrated with a needle-less syringe. $100 \mu \mathrm{M}$ ABA prepared in a buffer solution $(10 \mathrm{mM}$ HEPES, $0.5 \%$ Tween 20 ) was introduced under pressure into intracellular spaces. Control leaves were infiltrated with buffer alone. (2) The long-term treatment lasted $48 \mathrm{~h}$. Plants were sprayed with $100 \mu \mathrm{M}$ ABA (identical solution as that for the short-term treatment) or with buffer alone at 9 a.m. on two consecutive mornings. The spraying was done with hand-held spray bottles until the foliage was uniformly wetted. Plants were darkened overnight starting from 8 p.m. on the second day. One part of each plant was used the next morning for RNA isolation and the other part for chloroplast movement analysis. (3) In experiments involving mutants plants were sprayed with 100 $\mu \mathrm{M}$ ABA (solution and its application as in (2)) at $7 \mathrm{pm}$. and dark-adapted (and ABA-incubated) for at least $16 \mathrm{~h}$ before chloroplast movement measurement.

Analysis of the steady-state RNA level. Quantitative real-time PCR was performed to study the level of PHOT1 and PHOT2. After long-term ABA treatment, the plants used for RNA isolation were kept for $3 \mathrm{~h}$ either in the dark or in medium-intensity white light (100 $\mu \mathrm{mol} \mathrm{m} \mathrm{m}^{-2} \mathrm{~s}^{-1}$ ) in the growth chamber.

Ten leaves from at least six individual plants were pooled before RNA extraction. RNA was isolated with a Spectrum Plant Total Kit (Sigma-Aldrich) and digested with DNaseI (Fermentas) during purification on the column. The RNA concentration was determined using a NanoPhotometer (Implen $\mathrm{GmbH}$ ) and its integrity was checked by electrophoresis on 2\% agarose gel. cDNA was prepared with the RevertAid M-MuLV Reverse Transcriptase Kit (Fermentas) using random hexamer primers. Real time reverse-transcription PCR was performed with SYBR Green JumpStart Taq ReadyMix (Sigma Aldrich) and a thermal cycler (Rotor-Gene 6000, Corbett Research, Australia). cDNA corresponding to 50 ng of RNA was used in a single reaction and all reactions were run in duplicates. The PCR conditions and primer sequences for PHOT1 and PHOT2 were based on Łabuz and others (2012). UBQ10 was chosen as a reference gene because its expression was shown to be unaffected by $\mathrm{ABA}$ treatment and primer sequences were based on Czechowski and coworkers (2005). The specificity of the obtained products was verified on a dissociation curve at the end of each run and by $2 \%$ agarose gel electrophoresis.

Western blotting. The expression levels of phot1 and phot 2 proteins were determined using Western blot analysis. Plants were subjected to long-term ABA and dark/light treatments in the same way as for mRNA level analysis. Each sample consisted of 2-3 leaves from an individual plant. Samples were ground in liquid nitrogen, weighed and suspended in an appropriate amount of protein extraction buffer $(100 \mu \mathrm{l} / 10 \mathrm{mg}$ sample; 0.1 $\mathrm{M}$ Tris, $\mathrm{pH} 8.8,4 \%$ SDS, 2 mM phenylmethylsulphonyl fluoride (PMSF), 2\% $\beta$-mercaptoethanol). Samples were incubated at $80^{\circ} \mathrm{C}$ for $3 \mathrm{~min}$ and centrifuged at $16000 \times g, 4^{\circ} \mathrm{C}$ for $10 \mathrm{~min}$ (Sakamoto \& Briggs, 2002). The obtained protein extract was mixed with appropriate amounts of SDS loading buffer, heated at $95^{\circ} \mathrm{C}$ for $10 \mathrm{~min}$ and separated by SDS-PAGE. All gels were run in triplicate: one for Coomassie staining and two for Western blot analysis (phot1 and phot2). Western blotting was performed using antibodies purchased from Agrisera: primary anti-PHOT1 (AS10 720; 1:200) and anti-PHOT2 (AS10 721; 1:2000) antibodies, and secondary goat anti-rabbit IgG-horseradish peroxidase antibodies $(1: 25000)$. For a detailed description of anti-PHOT antibodies and Western blotting conditions see Labuz et al., 2015. Protein detection was performed using Clarity Western ECL substrate (Bio-Rad) and densitometric analysis carried out using ImageJ software. Results are the mean values from 9 samples, normalized to the total amount of protein in each sample. To account for differences between blots, the normalized values were divided by the chemiluminescent signal/protein content ratio averaged over all lanes in a blot.

Photometric method. Chloroplast movements induced by continuous blue light (BL, $460 \mathrm{~nm}$ ) were assessed using a double-beam photometer which records changes in red light transmittance $\left(660 \mathrm{~nm}, 0.1 \mu \mathrm{mol} \mathrm{m} \mathrm{m}^{-2}\right.$ $\mathrm{s}^{-1}$, modulated with the frequency of $800 \mathrm{~Hz}$ ) through the leaf (Walczak \& Gabryś, 1980). Leaf transmittance decreases in weak light (avoidance response) and increases in strong light (accumulation response) as a result of chloroplast redistribution. First, the initial transmittance level of leaves dark-adapted for at least $12 \mathrm{~h}$ was measured. Whenever possible, leaves with similar initial transmittance were chosen for one experiment. Subsequently, samples were illuminated with BL of different intensities, changed stepwise every $45 \mathrm{~min}$. In short- and long-term $\mathrm{ABA}$ treatment experiments the following $\mathrm{BL}$ intensities were used: $1.4 \mu \mathrm{mol} \mathrm{m} \mathrm{m}^{-2} \mathrm{~s}^{-1}$ (weak BL), $18 \mu \mathrm{mol} \mathrm{m} \mathrm{m}^{-2} \mathrm{~s}^{-1}$ (medium BL) and $108 \mu \mathrm{mol} \mathrm{m} \mathrm{m}^{-2} \mathrm{~s}^{-1}$ (strong BL). In the dose-response experiments performed on mutants, additional intermediate BL fluence rates were applied: 36 $\mu \mathrm{mol} \mathrm{m} \mathrm{m}^{-2} \mathrm{~s}^{-1}$ and $72 \mu \mathrm{mol} \mathrm{m} \mathrm{m}^{-2} \mathrm{~s}^{-1}$. The following parameters were measured/calculated for each response: (1) amplitude - transmittance change after 45 minutes, (2) velocity - first derivative of the initial linear fragment of the transmittance curve.

Bright field microscopy of leaf cross-sections. Hand-cut cross-sections were prepared from fresh leaves of WT and mutant plants, untreated or subjected to long-term ABA treatment. Sections were infiltrated with water and visualized using a Nikon Eclipse TE 200 (Japan) inverted microscope equipped with a $\times 100.25 \mathrm{NA}$ objective. The microscope was coupled to a QICAM (Evolution VF) cooled monochrome CCD digital camera and Image-Pro Plus software version 5.1 (Media Cybernetics Inc.).

ELISA experiments. WT $A$. thaliana plants were subjected to long-term ABA treatment. Subsequently, the plants were dark-adapted for $2 \mathrm{~h}$, the samples were collected, washed in distilled water and immediately lyophilized. The tissue analyzed for ABA content was combined from 4 plants. Experiments were performed twice. ABA was extracted according to Janowiak and others (2002) and its concentration in leaves was quantified 


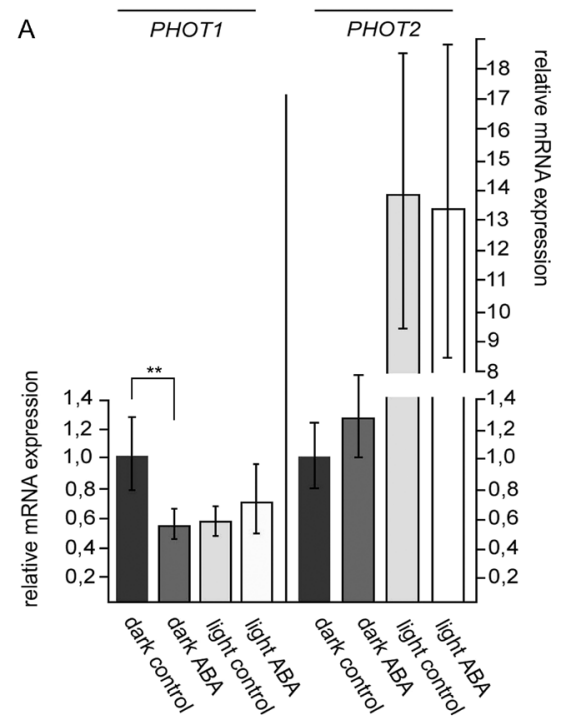

B

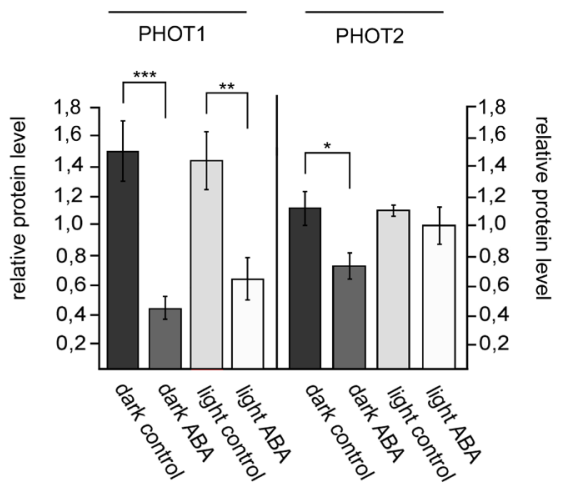

Figure 1. The expression of phototropin 1 and phototropin2 in leaves of WT A. thaliana at mRNA (A) and protein (B) levels.

5 -week-old plants were pretreated with control buffer or $100 \mu \mathrm{M} A B A$, dark-adapted overnight and then either illuminated with $100 \mu \mathrm{mol} \mathrm{m} \mathrm{m}^{-2} \mathrm{~s}^{-1}$ white fluorescent light in the growth chamber for $3 \mathrm{~h}$ (light) or left in the dark (dark). (A) Each bar corresponds to the average of at least three measurements from a pool of ten leaves collected from at least six different plants. All qRT-PCR reactions were run in duplicates. (B) Each bar corresponds to the average of 9 measurements of leaves collected from individual plants. All error bars represent SE. Asterisks indicate the statistical significance of differences between control and ABA-treated plants ( $p$-values calculated using Student's $t$-test: ${ }^{*} p=0.01-0.05,{ }^{* *} p=0.001-0.01,{ }^{* * *} p<0.001$ ).

by ELISA according to the Walker-Simmons method (1987), using the MAC252 antibody.

Statistical analysis. Unpaired Student's $t$-test was performed using GraphPad InStat version 3.10 for Windows, GraphPad Software, San Diego California USA, www.graphpad.com.

\section{RESULTS}

\section{Analysis of phototropin expression patterns}

We investigated the influence of exogenously applied ABA on phototropin mRNA and protein levels in mature leaves of dark-adapted or irradiated Arabidopsis plants (Fig. 1A). Light down-regulated PHOT1 and up-regulated PHOT2 expression. The effect of ABA on PHOT1 expression depended on light conditions. While PHOT1 mRNA level decreased significantly upon ABA treatment in dark-adapted leaves, it did not change in leaves of plants illuminated with white light. By contrast, ABA had no significant effect on the expression of PHOT2, either in dark-adapted or illuminated leaves.

At the protein level no effect of light on phototropin expression could be observed, but at the same time the influence of ABA was more pronounced (Fig. 1B). PHOT1 was significantly down-regulated by ABA in both darkness and light, whereas PHOT2 only in darkness. In the case of both phototropins the effect of $\mathrm{ABA}$ was stronger in darkness.

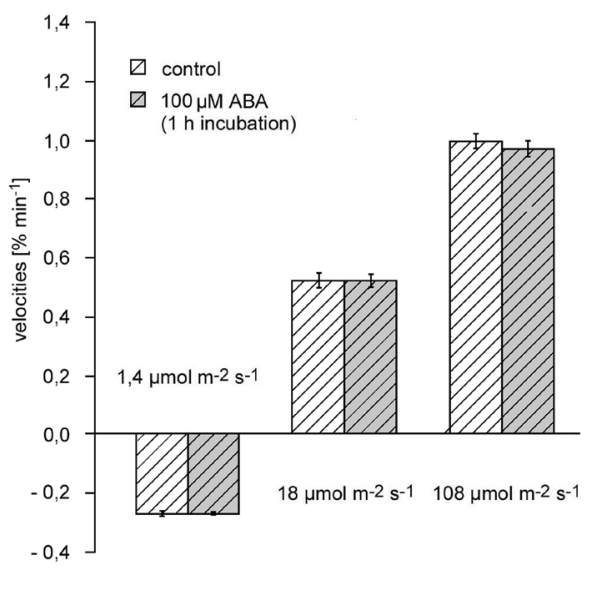

Figure 2. Amplitudes (left) and velocities (right) of transmittance changes reflecting chloroplast relocations induced by continuous blue light of increasing fluence rates (indicated on graph, each step $45 \mathrm{~min}$ ) in WT A. thaliana leaves pretreated with $100 \mu \mathrm{M}$ ABA for $1 \mathrm{~h}$ in the dark.

Results are means of 11 (control samples) or 12 (ABA-treated samples) independent experiments, error bars represent S.E. No statistically significant differences were detected between control and treated plants (all $p$-values calculated using Student's $t$-test above 0.05). 

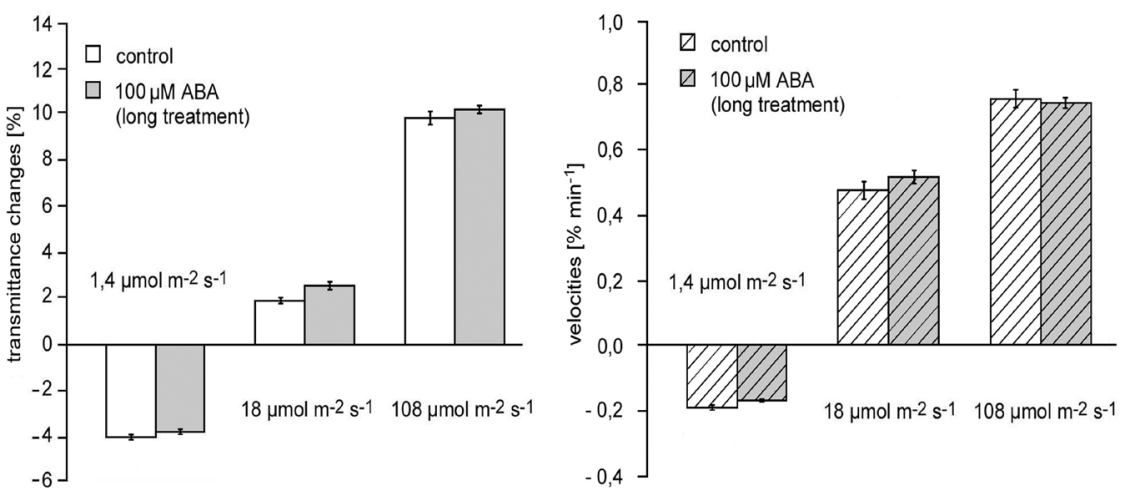

Figure 3. Amplitudes (left) and velocities (right) of transmittance changes reflecting chloroplast relocations induced by continuous blue light of increasing fluence rates (indicated on graph, each step $45 \mathrm{~min}$ ) in WT A. thaliana leaves pretreated with $100 \mu \mathrm{M}$ ABA for $48 \mathrm{~h}$.

Results are means of 12 (control samples) or 15 (ABA-treated samples) independent experiments, error bars represent S.E. No statistically significant differences were detected between control and treated plants (all p-values calculated using Student's $t$-test above 0.05 ).

\section{Chloroplast movements - short-term ABA exposure}

To investigate the interplay between $\mathrm{ABA}$ and light signaling pathways in chloroplast movements we performed a series of photometric studies. In the first experiment, the effects of short-term ABA exposure $(100 \mu \mathrm{M}, 1 \mathrm{~h})$ were tested. The extreme BL fluence rates applied caused maximal accumulation $(1.4 \mu \mathrm{mol}$ $\left.\mathrm{m}^{-2} \mathrm{~s}^{-1}\right)$ and avoidance responses $\left(108 \mu \mathrm{mol} \mathrm{m} \mathrm{m}^{-2} \mathrm{~s}^{-1}\right)$ of chloroplasts, whereas irradiation with intermediate $\mathrm{BL}$ $\left(18 \mu \mathrm{mol} \mathrm{m} \mathrm{m}^{-2} \mathrm{~s}^{-1}\right)$ produced an incomplete avoidance response (Trojan \& Gabryś, 1996). No significant differences in amplitudes or velocities were detected between ABA-treated and control leaves in any of the responses (Fig. 2).

\section{Chloroplast movements - long-term ABA exposure}

In the next experiment, the influence of long-term ABA treatment on chloroplast movements was investigated. The exposure to abscisic acid was extended to $48 \mathrm{~h}$. During that time plants were sprayed twice with $100 \mu \mathrm{M}$ ABA. Similarly as in the short-term experiment, ABA did not influence the amplitudes or velocities of any of the chloroplast responses (Fig. 3).

In order to exclude the possibility that ABA did not reach the mesophyll cells we measured its concentration in the leaf tissue using ELISA. The level of abscisic
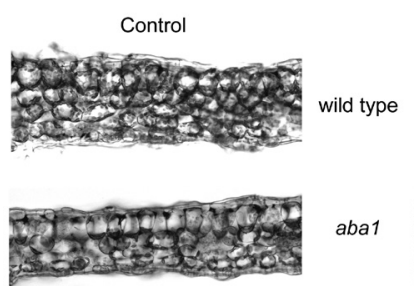

aba1
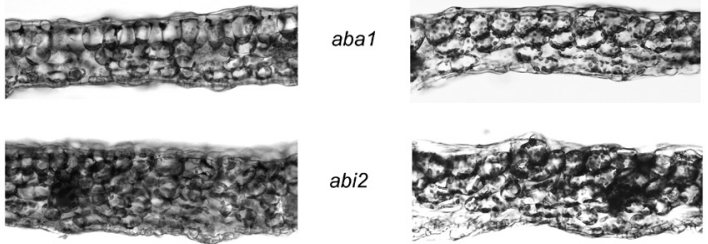

abi2
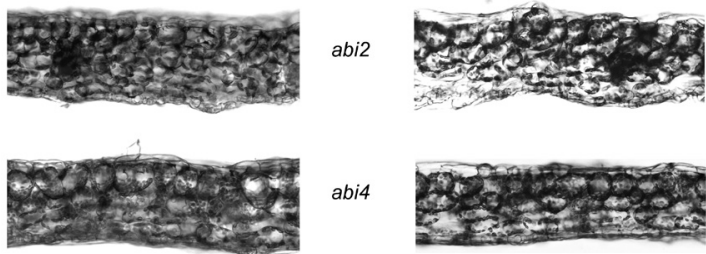

$a b i 4$

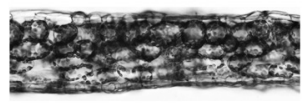

Figure 4. Cross-sections of fresh leaves of $A$. thaliana WT and aba1, abi2, abi4 mutant plants, untreated or subjected to longterm ABA treatment (100 $\mu \mathrm{M}, 48 \mathrm{~h})$. acid was 2.8 times higher in the treated plants than in the control ones (ABA-treated samples $4.0 \pm 0.15 \mathrm{nmol}$ $\mathrm{g}^{-1} \mathrm{DW}$ versus control $\left.1.4 \pm 0.33 \mathrm{nmol} \mathrm{g}^{-1} \mathrm{DW}\right)$, which confirms the effectiveness of ABA treatment. The experiment was performed twice with four plants per group. No differences in leaf anatomy and condition between control and ABA-treated plants could be observed (Fig. 4).

\section{Chloroplast movements in ABA mutants}

To further elucidate the interplay of $\mathrm{ABA}$ and blue light-controlled chloroplast movements, we investigated selected Arabidopsis ABA signaling and biosynthesis mutants: abi4-1, abi2-1 (aba insensitive, hereafter referred to as abi4, abi2) and aba1-6 (abscisic acid, hereafter referred to as $a b a 1)$.

A dose-response analysis of chloroplast movements was performed in the described mutants, using 5 increasing BL intensities (Fig. 5). All mutants performed accumulation responses which were statistically indistinguishable from WT. At higher BL intensities (18$108 \mu \mathrm{mol} \mathrm{m} \mathrm{m}^{-2} \mathrm{~s}^{-1}$ ) only abi4 responses were comparable with those of WT plants. The avoidance responses of both abi2 and aba1 chloroplasts were significantly lower than in WT plants starting from the fluence rate of $36 \mu \mathrm{mol} \mathrm{m} \mathrm{m}^{-2} \mathrm{~s}^{-1}$. The $p$-values of differences between WT and mutant plants at 36, 72 and $108 \mu \mathrm{mol} \mathrm{m} \mathrm{m}^{-2} \mathrm{~s}^{-1}$ were respectively : $p=0.0011, p=0.0194, p=0.0238$ for abi2 and $p=0.0491, p=0.0245, p=0.0104$ for aba1. At $18 \mu \mathrm{mol} \mathrm{m} \mathrm{m}^{-2} \mathrm{~s}^{-1}$ abi2 exibited a very weak accumulation response, in contrast to WT and the other mutants which performed an avoidance response at this light intensity. To check whether the results of chloroplast movement measurements could be affected by differences in leaf architecture, cross-sections of mutant leaves were prepared. Although some differences in cell size and leaf thickness were observed, no serious abnormalities were visible (Fig. 4).

\section{Supplementation experiments}

We carried out supplementation experiments to determine whether the addition of ABA restores avoidance responses in abi2 and aba1 mutants (Fig. 6). Mutant and WT plants were sprayed with $100 \mu \mathrm{M}$ ABA and chloroplast movements measured after $16 \mathrm{~h}$ of dark adaptation. Only avoidance responses induced by 18, 36 and $108 \mu \mathrm{mol} \mathrm{m} \mathrm{m}^{-2} \mathrm{~s}^{-1}$ were tested since chloroplast accumulation was not impaired in the studied 


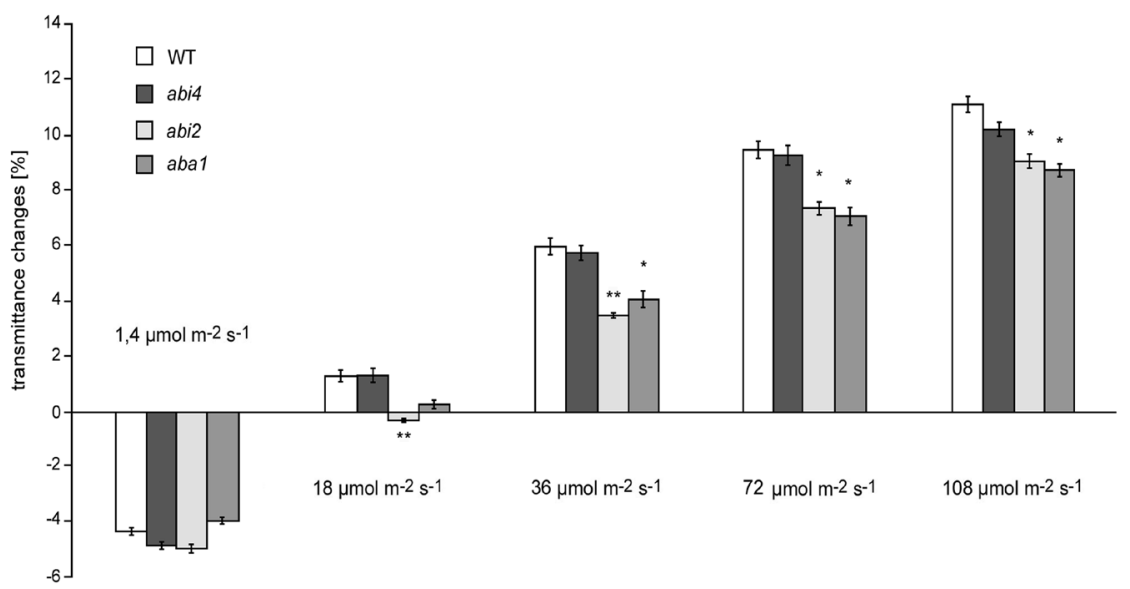

Figure 5. Amplitudes of transmittance changes reflecting chloroplast relocations induced by continuous blue light of increasing fluence rates (indicated on graph, each step $45 \mathrm{~min}$ ) in leaves of $A$. thaliana: WT, abi4, abi2 and aba1.

Results are means of 6 to 8 independent experiments, error bars represent S.E. Asterisks indicate the statistical significance of differences between wild type and mutant plants $(p$-values calculated using Student's $t$-test: $\left.{ }^{*} p=0.01-0.05,{ }^{* *} p=0.001-0.01\right)$.

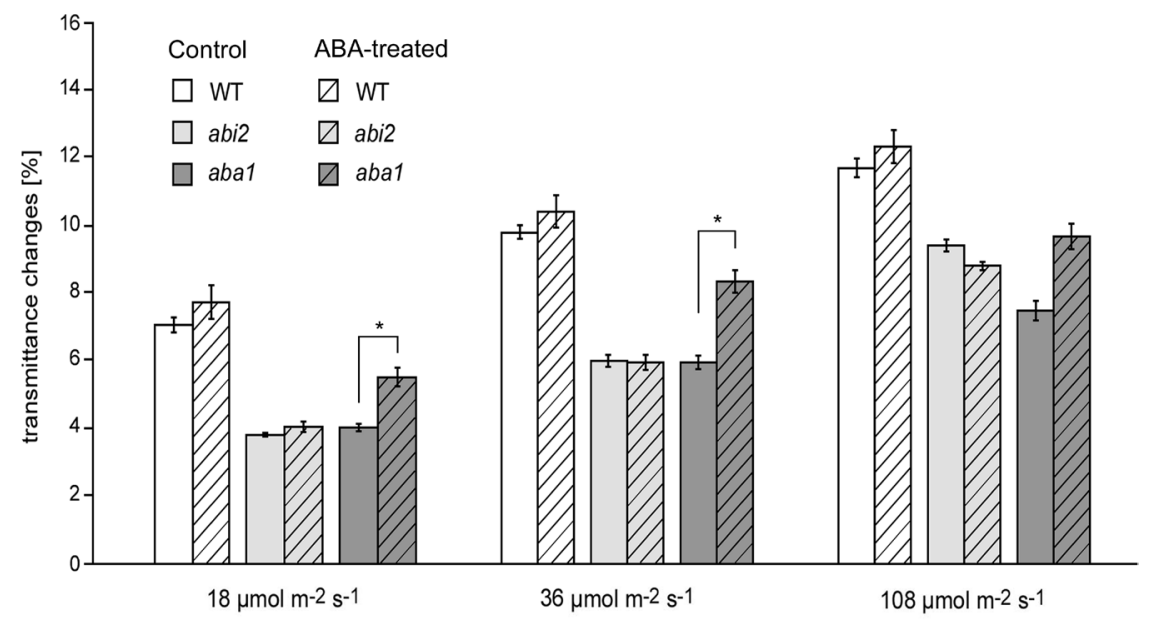

Figure 6. Amplitudes of transmittance changes reflecting chloroplast relocations induced by continuous blue light of increasing fluence rates (indicated on graph, each step $45 \mathrm{~min}$ ) in leaves of $A$. thaliana WT, abi2 and aba1, pretreated with $100 \mu \mathrm{M}$ ABA for $16 \mathrm{~h}$.

Results are means of 6 independent experiments, error bars represent S.E. Asterisks indicate the statistical significance of differences between the respective control and ABA-treated plants ( $p$-values calculated using Student's $t$-test: $\left.{ }^{*} p=0.01-0.05\right)$.

mutants. The responses of WT and abi2 chloroplasts to all three BL intensities were unaffected by ABA treatment. By contrast, exogenous ABA treatment of aba1 plants visibly enhanced chloroplast responses. Although the resulting amplitudes were still visibly lower than those of untreated and ABA-treated WT plants, the differences between control and ABA-treated aba1 plants were statistically significant at 18 and $36 \mu \mathrm{mol}$ $\mathrm{m}^{-2} \mathrm{~s}^{-1}(p=0.0394, p=0.0157)$ and on the borderline of significance at $108 \mu \mathrm{mol} \mathrm{m} \mathrm{m}^{-2} \mathrm{~s}^{-1}(p=0.0529)$. Thus, the avoidance response in the aba1 mutant can be partially rescued by exogenous $\mathrm{ABA}$ while changes introduced by the abi2 mutation cannot be compensated in this way. Leaf cross-sections of ABA-sprayed plants were performed to check for potential adverse effects of this treatment. No differences in leaf anatomy and condition between control and ABA-treated WT and mutant plants could be seen (Fig. 4).

\section{DISCUSSION}

Considerable progress has been made in the studies of chloroplast movements since the first publication by Senn in 1908. In the last two decades the photoreceptors have been discovered (Christie et al., 1998; Jarillo et al., 2001; Kagawa et al., 2001). While the mechanisms of chloroplast movements became more comprehensible, numerous questions, particularly those concerning signal transduction, still remain unanswered. The complexity of the phenomenon on the one hand and the photoprotective role of the avoidance response on the other (Kasahara et al., 2002; Sztatelman et al., 2010) stimulated us to inquire how the stress hormone ABA is involved in the studied mechanism. A link between ABA and chloroplast movements has already been shown by Rojas-Pierce and coworkers (2014). We tried to further elucidate this question and investigate the potential mechanisms of ABA interactions with the chloroplast movement signaling pathway.

\section{Analysis of phototropin expression patterns}

The expression of PHOT1 and PHOT2 was strongly regulated by light, which is consistent with the results of Labuz and coworkers (2012), but almost unaffected by ABA (Fig. 1A). Only PHOT1 was downregulated by $\mathrm{ABA}$ in the dark Interestingly, at the protein level the expression pattern of phototropins was completely different. The levels of phototropin proteins were unaffected by light, but decreased after ABA treatment, especially in the case of PHOT1 (Fig. 1B). The observed discrepancies between phototropin mRNA and protein levels point to a complex regulation of the expression of these photoreceptors. The effect of light on phototropin expression at transcript level and its subsequent lack at the protein level are surprising, but consistent with the findings of Sztatelman and coworkers (2016). On the contrary, the influence of ABA on phototropin expression is negligible at mRNA level, but prominent at the protein level. This suggests that other regulatory factors act downstream of light to regulate phototropin protein levels and ABA could be one of them. Moreover, the downregulation of phototropin protein levels by ABA seems in line with the antagonistic roles of phototropins and $\mathrm{ABA}$ in the control of stomatal movement. 


\section{Chloroplast movements - short-term and long-term ABA exposure}

Neither short-term (1 h) nor long-term treatment (2 days) exogenous ABA treatment affected chloroplast responses to blue light (Fig. 2 and 3). An analysis of ABA levels in leaves confirmed that the hormone treatment was effective. This shows that exogenous ABA does not provide a direct signal to chloroplast relocation in W'T Arabidopsis mesophyll cells. Moreover the results of longterm ABA treatment experiments show that the downregulation of phototropin protein levels by ABA does not affect chloroplast movements.

\section{Chloroplast movements in ABA mutants}

Finally, we investigated the role of endogenous $\mathrm{ABA}$ in chloroplast movements using three different abscisic acid mutants, abi4, abi2, aba1. The most remarkable observation was that all mutants showed accumulation responses in weak light similar to wild type plants. Differences were found only in the avoidance responses activated by strong light (Fig. 4). The differential effects of the investigated mutations on the accumulation and avoidance reactions are in line with all former evidence showing that these two types of responses have distinct mechanisms (Grabalska \& Malec, 2004; Krzeszowiec \& Gabryś, 2007; Aggarwal et al., 2013). The main difference between the weak- and the strong-light response lies in the accumulation response being controlled by phototropin 1 and phototropin2 and the avoidance response mainly by phototropin2. Only recently has it been revealed that phosphoinositides and calcium ions play differential roles in signal transduction in phot1- and phot2-controlled pathways (Aggarwal et al., 2013). Also some of the proteins involved in the signal transduction pathway (JAC1, PMI2, WEB1) were shown to play a major role only in one of the responses (Suetsugu et al., 2005; Luesse et al., 2006; Kodama et al., 2010). Our results, demonstrating that the studied ABA mutants have typical accumulation and lesser avoidance responses, are consistent with all these facts.

The chloroplast responses of the abi4 mutant were comparable with wild type plants, which is in line with the results of Rojas-Pierce and coworkers (2014). The ABI4 protein was shown to play a role in many different physiological processes e.g. seed development, germination and seedling establishment, root development and pathogen responses, and to be involved in ABA, sugar (i.a. trehalose), nitrogen, ascorbate and ROS signaling (reviewed in León et al., 2013). The ABI4 transcription factor was also shown to play a central role in plastidto-nucleus retrograde signaling (Koussevitzky et al., 2007; León et al., 2013). The lack of differences in accumulation and avoidance responses between abi4 and wild type indicates that no protein encoded by genes regulated by ABI4 is involved in the chloroplast movement mechanism in Arabidopsis.

The remaining two mutants, aba1 and, abi2 had significantly lower amplitudes of chloroplast responses in strong light as compared with the wild type. A partial inhibition of chloroplast responses to strong BL in aba1 was already shown by DeBlasio and coworkers (2005) and Rojas-Pierce and coworkers (2014). To understand whether this effect is due to the reduced endogenous ABA level in this mutant we supplemented the plants with exogenous ABA. This treatment significantly enhanced chloroplast movements, partially rescuing the mutant phenotype (Fig. 6). The obtained result clearly shows that physiological endogenous $\mathrm{ABA}$ levels are necessary for the normal functioning of chloroplast movements. On the other hand, the reduced chloroplast avoidance in abal can be partly due to the impairment of the xanthophyll cycle which was shown to affect chloroplast movements (Tlałka et al., 1999). However, taking into account the role of zeaxanthin epoxidase in both ABA biosynthesis and the xanthophyll cycle it is difficult to definitely distinguish between the impact of each of these processes on chloroplast movement.

Reduced chloroplast movements in abi2 plants also point to the involvement of $\mathrm{ABA}$ in the positive regulation of chloroplast movements, and more specifically, to the role of ABA perception through the PYR/PYL/ RCAR-PP2C-SnRK2 signalosome. A similar result was obtained for the abi1-1 mutant, defective in the $A B I 1$ gene, which is a close homolog of $A B I 2$ (Rojas-Pierce et al., 2014). Additionally, in our study abi2 plants were subjected to exogenous ABA treatment but it failed to restore normal chloroplast movements. This provides indirect evidence that the abnormal chloroplast movement in abi2 is indeed related to the impaired ABA signaling in this mutant. The results obtained for $a b a 1$ and abi2 are consistent with the idea that $\mathrm{ABA}$ acts as a positive regulator of chloroplast responses. ABA appears to sensitize plants to light and to promote a stronger avoidance reaction, which is compatible with the role of avoidance as a stress response on the one hand, and $\mathrm{ABA}$ as a stress hormone on the other hand. As already suggested by Rojas-Pierce and coworkers (2014), the PMI1 protein seems a good candidate for an integrator of $\mathrm{ABA}$ and light signals to control chloroplast movements, possibly acting via calcium signaling.

Many genes involved in ABA biosynthesis and signaling, including $A B A 1$ and $A B I 4$ are regulated by sugars (reviewed in León \& Sheen, 2003). On the other hand, we have shown that sugars are involved in the regulation of chloroplast relocations (Banaś \& Gabryś, 2007; Eckstein et al., 2012). However, taken together our results suggest that $\mathrm{ABA}$ is not an intermediate in sugar signaling to chloroplast movement. Sugars inhibit both chloroplast accumulation and avoidance, whereas ABA is only involved in the avoidance response. The influence of sugars on chloroplast movements in ABA mutants has to be investigated to verify this hypothesis.

The functioning of ABA in the modulation of chloroplast responses should also be considered in the context of cross-talk with other hormones. As can be seen on the example of stomatal movement regulation, the interactions between phototropin and hormone signaling can be very complex and the effects of one hormone may vary depending on the endogenous levels of others (Acharya \& Assmann, 2009). Until now, only the role of auxin in the regulation of chloroplast relocations has been studied (Eckstein et al., 2016). Several similarities between the involvements of ABA and auxin on chloroplast movements can be pointed out. Neither hormone affects chloroplast movements when applied directly to leaves. However, the disturbance of auxin and ABA homeostasis (by shoot decapitation and in the aba1 mutant, respectively) impairs chloroplast movements, but in both cases this can be partially overcome by exogenous hormone application. The analysis of auxin and ABA signaling mutants suggests that the effects of these hormones on the chloroplast movement mechanism are at least partially dependent on long term changes in gene expression. Among the differences between ABA and auxin action in the regulation of chloroplast movements is the involvement in only one (avoidance) or both chloroplast reactions respectively. However, no direct clues to the 
cross-talk between different hormones in the control of chloroplast movements have been found yet. The effect of auxin homeostasis disturbance (by shoot decapitation and auxin transport inhibitors) on endogenous hormone levels has been studied, but no major changes have been observed in the content of ABA and several cytokinins (Eckstein et al., 2016). Moreover, the exogenous application of cytokinins to leaves, alone or with auxin, did not affect chloroplast movements (unpublished results).

\section{Differential role of $A B A$ in chloroplast movements in mesophyll vs guard cells}

The effect of exogenous ABA on chloroplast movements in mesophyll and guard cells differs significantly. ABA disturbs chloroplast relocations in guard cells, but not in the mesophyll of wild type plants. This may point to differences in signaling pathways and mechanisms of chloroplast relocations in both types of cells.

To date, only two papers have been published which focus on chloroplast movements in guard cells (Königer et al., 2010; Wang et al., 2011). The authors state that chloroplast movements in guard cells are similar to those observed in mesophyll cells. This comparison should be made with great care because both the geometry and functioning of guard cells are different from mesophyll cells. Moreover the chloroplast positioning in guard cells was defined and measured in a different way than the avoidance and accumulation responses in the mesophyll tissue. The former was analyzed along horizontal (epidermal/pore/center position in a guard cell) and vertical (upper/lower/middle part of the cell) axes (Königer et al., 2010). The tissue was fixed with glutaraldehyde which may be a source of artifacts due to the differential thickening of the guard cell walls. Similar to the mesophyll, chloroplast responses differed to some extent in phot1-5/phot2 and phot2 mutants as compared to wild type plants. (Königer et al., 2010). Nevertheless, two important differences between chloroplast responses in guard and mesophyll cells should be pointed out. First, cytochalasin B did not stop the movements completely in guard cells (Wang et al., 2011) which suggests that they are only partly based on the actin cytoskeleton. Secondly, guard cells move themselves while mesophyll cells do not. Consequently, chloroplast relocations in guard cells might be due in part to the movement of the whole cell.

\section{CONCLUSIONS}

ABA is not a key player in the control of chloroplast responses in the mesophyll of Arabidopsis, in contrast to guard cells. Exogenous ABA affects the expression of phototropins at the protein level, but this is not reflected in blue light-activated chloroplast relocations. On the other hand, the impairment of chloroplast avoidance in aba1 and abi2 mutants point to the role of ABA in regulating this response. Furthermore, the results of mutant supplementation with exogenous ABA show that not only physiological ABA levels, but also $\mathrm{ABA}$ perception via the PYR/PYL/RCAR-PP2C-SnRK2 signaling complex, are important for normal chloroplast movement. In physiological conditions, the full toolkit of proteins available in wild type plants makes the influence of ABA invisible.

Overall, ABA appears to enhance plant sensitivity to light and promote the avoidance response. This seems in line with the role of this hormone in drought stress, which is often a consequence of strong light stress in the natural environment. The avoidance reaction is a photoprotective response to excess light. ABA may therefore function as a signal linking plant responses to the two types of stress.

\section{Acknowledgements}

The authors wish to thank Dr. Olga Sztatelman for critical reading of the manuscript.

Financial support: Financial support from the Polish National Science Centre, grant no. 2011/01/B/ NZ3/02160 "Phototropin signaling in higher plants" is gratefully acknowledged. The Faculty of Biochemistry, Biophysics and Biotechnology of the Jagiellonian University is a partner of the Leading National Research Center (KNOW) supported by the Ministry of Science and Higher Education and benefits from the structural funds from the European Union - grant no: POIG.02.01.0012-064/08.

\section{Conflict of interests}

The authors declare that they have no conflict of interests.

\section{REFERENCES}

Acharya BR, Assmann SM (2009) Hormone interactions in stomatal function. Plant Mol Biol 69: 451-462. https://doi.org/10.1007/ s11103-008-9427-0..

Aggarwal C, Labuz J, Gabryś H (2013) Phosphoinositides play differential roles in regulating phototropin1-and phototropin2-mediated chloroplast movements in Arabidopsis. PLoS One 8: e55393. https:// doi.org/journal.pone.0055393 .

Anielska-Mazur A, Bernaś T, Gabryś H (2009) In vivo reorganization of the actin cytoskeleton in leaves of Nicotiana tabacum L. transformed with plastin-GFP: Correlation with light-activated chloroplast responses. BMC-Plant Biol 64: 1-14. https://doi. org/10.1186/1471-2229-9-64.

Assmann SM, Schwartz A (1992) Synergistic effect of light and fusicoccin on stomatal opening. Plant Physiol 98: 1349-1355. https://doi. org/10.1104/pp.98.4.1349.

Assmann SM, Snyder JA, Lee Y-RJ (2000) ABA-deficient (aba1) and ABA-insensitive (abi1-1, abi2-1) mutants of Arabidopsis have a wildtype stomatal response to humidity. Plant Cell Environ 23: 387-395. https://doi.org/10.1046/j.1365-3040.2000.00551.x.

Augustynowicz J, Krzeszowiec W, Gabrys H (2009) Acquisition of plastid movement responsiveness to light during mesophyll cell differentiation. Int J Dev Biol 53: 121-127. https://doi.org/10.1387/ ijdb.062140ja.

Banaś AK, Aggarwal C, Labuz J, Sztatelman O, Gabryś H (2012) Blue light signalling in chloroplast movements. J Exp Bot 63: 1559-1574. https://doi.org/10.1093/jxb/err429.

Banaś AK, Gabryś H (2007) Influence of sugars on blue light-induced chloroplast relocations. Plant Signal Behav 2: 221-230. https://doi. org/ 10.4161/psb.2.4.4392.

Barrero JM, Piqueras P, González-Guzmán M, Serrano R, Rodríguez PL, Ponce MR, Micol JL (2005) A mutational analysis of the ABA1 gene of Arabidopsis thaliana highlights the involvement of ABA in vegetative development. I Exp Bot 56: 2071-2083. https://doi.org/ 10.1093/jxb/eri206.

Blackman PG, Davies WJ (1983) The effects of cytokinins and ABA on stomatal behaviour of maize and Commelina. J Exp Bot 34: 16191626. https://doi.org/10.1093/jxb/34.12.1619.

Brady SM, McCourt P (2003) Hormone cross-talk in seed dormancy. J Plant Growth Regul 22: 25-31. https://doi.org/10.1007/s00344-0030018-7.

Cao FY, Yoshioka K, Desveaux D (2011) The roles of ABA in plantpathogen interactions. Journal Plant Res 124: 489-499. https://doi. org/10.1007/s10265-011-0409-y.

Christie JM, Reymond P, Powell GK, Bernasconi P, Raibekas AA, Liscum E, Briggs WR (1998). Arabidopsis NPH1: a flavoprotein with the properties of a photoreceptor for phototropism. Science 282: 1698-1701. https://doi.org/ 10.1126/science.282.5394.1698.

Czechowski T, Stitt M, Altmann T, Udvardi MK, Scheible WR (2005) Genome-wide identification and testing of superior reference genes for transcript normalization in Arabidopsis. Plant Physiol 139: 5-17. https://doi.org/10.1104/pp.105.063743. 
DeBlasio SL, Luesse DL, Hangarter RP (2005) A plant-specific protein essential for blue-light-induced chloroplast movements. Plant Physiol 139: 101-114. https://doi.org/10.1104/pp.105.061887.

Desikan R, Last K, Harrett-Williams R, Tagliavia C, Harter K, Hooley R, Hancock JT, Neill, SJ (2006) Ethylene-induced stomatal closure in Arabidopsis occurs via AtrbohF-mediated hydrogen peroxide synthesis. The Plant Journal 47: 907-916. https://doi.org/10.1111/ j.1365-313X.2006.02842.x.

Dubas E, Janowiak F, Krzewska M, Hura T, Zur I (2013) Endogenous ABA concentration and cytoplasmic membrane fluidity in microspores of oilseed rape (Brassica napus L.) genotypes differing in responsiveness to androgenesis induction. Plant Cell Rep 32: 14651475. https://doi.org/10.1007/s00299-013-1458-6.

Eckstein A, Krzeszowiec W, Waligórski P, Gabryś H (2016) Auxin and chloroplast movements. Physiol Plantarum 156: 351-366. https://doi. org/10.1111/ppl.12396.

Eckstein A, Zięba P, Gabryś H (2012) Sugar and light effects on the condition of the photosynthetic apparatus of Arabidopsis thaliana cultured in vitro. J Plant Growth Regul 31: 90-101 https://doi. org/10.1007/s00344-011-9222-z.

Finkelstein RR (1994) Mutations at two new Arabidopsis ABA response loci are similar to the abi3 mutations. Plant J 5: 765-771. https:// doi.org/10.1046/j.1365-313X.1994.5060765.x.

Finkelstein RR, Wang ML, Lynch TJ, Rao S, Goodman HM (1998) The Arabidopsis abscisic acid response locus ABI4 encodes an APETALA2 domain protein. Plant Cell 10: 1043-1054. https://doi. org/10.1105/tpc.10.6.1043.

Gabryś H (2004) Blue light-induced orientation movements of chloroplasts in higher plants: Recent progress in the study of their mechanisms. Acta Physiol Plant 26: 473-478. https://doi.org/10.1007/ s11738-004-0038-3.

Gabryś H (2012) Blue-Light-Activated Chloroplast Movements: Progress in the Last Decade. In Progress in Botany 73. Lüttge U, Beyschlag W, Büdel B, Francis D eds, pp 189-205. Springer Berlin Heidelberg. https://doi.org/10.1007/978-3-642-22746-2_7.

Gabryś H, Krzeszowiec W (2012) Chloroplast movements induced by light: diversity of mechanisms in various taxa. In Biological diversity. Laska G ed, pp 9-24. Bialystok: Polish Botanical Society.

Grabalska M, Malec P (2004) Blue Light-induced chloroplast reorientations in Lemna trisulca L. (Duckweed) are controlled by two separable cellular mechanisms as suggested by different sensitivity to Wortmannin. Photochem Photobiol 79: 343-348. https://doi. org/10.1111/j.1751-1097.2004.tb00019.x.

Haubrick LL, Torsethaugen G, Assmann SM (2006) Effect of brassinolide, alone and in concert with abscisic acid, on control of stomatal aperture and potassium currents of Vicia faba guard cell protoplasts. Physiol Plantarum 128: 134-143. https://doi.org/10.1111/ j.1399-3054.2006.00708.x.

Haupt W (1999) Chloroplast movement: from phenomenology to molecular biology. In Progress in Botany. Esser K, Kadereit JW, Runge M eds, pp 3-36. Springer Berlin Heidelberg. https://doi. org/10.1007/978-3-642-59940-8_1.

Haupt W, Scheuerlein R (1990) Chloroplast movement. Plant Cell Environ 13: 595-614. https://doi.org/10.1111/j.1365-3040.1990. tb01078.x.

Hubbard KE, Nishimur N, Hitomi K, Getzoff ED, Schroeder JI (2010) Early abscisic acid signal transduction mechanisms: newly discovered components and newly emerging questions. Genes Dev 24: 1695-1708. https://doi.org/10.1101/gad.1953910.

Inoue SI, Kinoshita T, Takemiya A, Doi M, Shimazaki KI (2008) Leaf positioning of Arabidopsis in response to blue light. Mol Plant 1: 15-26. https://doi.org/10.1093/mp/ssm001.

Iwabuchi K, Sakai T, Takagi S (2007) Blue light-dependent nuclear positioning in Arabidopsis thaliana leaf cells. Plant Cell Physiol 48: 12911298. https://doi.org/10.1093/pcp/pcm095.

Jarillo JA, Gabrys H, Capel J, Alonso JM, Ecker JR, Cashmore AR (2001) Phototropin-related NPL1 controls chloroplast relocation induced by blue light. Nature 410: 952-954. https://doi. org/10.1038/35073622.

Kadota A, Yamada N, Suetsugu N, Hirose M, Saito C, Shoda K, Ichikawa S, Kagawa T, Nakanod A, Wada M (2009) Short actin-based mechanism for light-directed chloroplast movement in Arabidopsis. Proc Natl Acad Sci USA 106: 13106-13111. https://doi. org/10.1073/pnas.0906250106.

Kagawa T, Sakai T, Suetsugu N, Oikawa K, Ishiguro S, Kato T, Tabata S, Okada K, Wada M (2001) Arabidopsis NPL1: a phototropin homolog controlling the chloroplast high-light avoidance response. Science 291: 2138-2141. https://doi.org/10.1126/science.291.5511.2138.

Kasahara M, Kagawa T, Oikawa K, Suetsugu N, Miyao M, Wada M (2002) Chloroplast avoidance movement reduces photodamage in plants. Nature 420: 829-832. https://doi.org/10.1038/nature01213.

Kinoshita T, Shimazaki KI (2001) Analysis of the phosphorylation level in guard-cell plasma membrane $\mathrm{H}^{+}$-ATPase in response to fusicoccin. Plant Cell Physiol 42: 424-432. https://doi.org/10.1093/pcp/ pce055.
Kinoshita T, Doi M, Suetsugu N, Kagawa T, Wada M, Shimazaki KI (2001) Phot1 and phot2 mediate blue light regulation of stomatal opening. Nature 414: 656-660. https://doi.org/10.1038/414656a.

Kodama Y, Suetsugu N, Kong SG, Wada M (2010). Two interacting coiled-coil proteins, WEB1 and PMI2, maintain the chloroplast photorelocation movement velocity in Arabidopsis. Proc Natl Acad Sci USA 107: 19591-19596. https://doi.org/10.1073/pnas.1007836107.

Koornneef M, Reuling G, Karssen CM (1984) The isolation and characterization of abscisic acid-insensitive mutants of Arabidopsis thaliana. Physiol Plant 61: 377-383. https://doi.org/10.1111/j.1399-3054.1984. tb06343.x.

Königer M, Jessen B, Yang R, Sittler D, Harris GC (2010) Light, genotype, and abscisic acid affect chloroplast positioning in guard cells of Arabidopsis thaliana leaves in distinct ways. Photosynth Res 105: 213-227. https://doi.org/10.1007/s11120-010-9580-6.

Koussevitzky S, Nott A, Mockler TC, Hong F, Sachetto-Martins G, Surpin M, Lim J, Mittler R, Chory J (2007) Signals from chloroplasts converge to regulate nuclear gene expression. Science 316: 715-719. https://doi.org/10.1126/science. 1140516.

Krzeszowiec W, Rajwa B, Dobrucki J, Gabryś H (2007) Actin cytoskeleton in Arabidopsis thaliana under blue and red light. Biol Cell 99: 251-260. https://doi.org/10.1042/BC20060077.

Krzeszowiec W, Gabrys H (2007) Phototropin mediated relocation of myosins in Arabidopsis thaliana. Plant Signal Behav 2: 333-336. https://doi.org/10.4161/psb.2.5.4509.

León P, Sheen J (2003) Sugar and hormone connections. Trends Plant Sci 8: 110-116. https://doi.org/10.1016/S1360-1385(03)00011-6.

León P, Gregorio J, Cordoba E (2013) ABI4 and its role in chloroplast retrograde communication. Front Plant Sci 3: 304. https://doi. org/10.3389/fpls.2012.00304.

Leung J, Bouvier-Durand M, Morris PC, Guerrier D, Chefdor F, Giraudat J (1994) Arabidopsis ABA response gene ABI1: features of a calcium-modulated protein phosphatase. Science 264: 1448-1451. https://doi.org/10.1126/science.7910981.

Leung J, Merlot S, Giraudat J (1997) The Arabidopsis ABSCISIC ACID-INSENSITIVE2 (ABI2) and ABI1 genes encode homologous protein phosphatases $2 \mathrm{C}$ involved in abscisic acid signal transduction. Plant Cell 9: 759-771. https://doi.org/10.1105/tpc.9.5.759.

Lohse G, Hedrich R (1992) Characterization of the plasma-membrane $\mathrm{H}^{+}$-ATPase from Vicia faba guard cells. Planta 188: 206-214. https://doi.org/10.1007/BF00216815.

Luesse DR, DeBlasio SL, Hangarter RP. (2006) Plastid movement impaired 2, a new gene involved in normal blue-light-induced chloroplast movements in Arabidopsis. Plant Physiol 141: 1328-1337. https://doi.org/10.1104/pp.106.080333.

Labuz J, Sztatelman O, Banaś AK, Gabryś H (2012) The expression of phototropins in Arabidopsis leaves: developmental and light regulation. J Exp Bot 63: 763-771. https://doi.org/10.1093/jxb/ers061.

Labuz J, Hermanowicz P, Gabryś H (2015) The impact of temperature on blue light induced chloroplast movements in Arabidopsis thaliana. Plant Science 239: 238-249. https://doi.org/10.1016/j.plantsci.2015.07.013.

Ma Y, Szostkiewicz I, Korte A, Moes D, Yang Y, Christmann A, Grill E (2009) Regulators of PP2C phosphatase activity function as abscisic acid sensors. Science 324: 1064-1068. https://doi.org/10.1126/ science. 1172408.

Marin E, Nussaume L, Quesada A, Gonneau M, Sotta B, Hugueney P, Frey A, Marion-Poll, A (1996) Molecular identification of zeaxanthin epoxidase of Nicotiana plumbaginifolia, a gene involved in abscisic acid biosynthesis and corresponding to the ABA locus of Arabidopsis thaliana. EMBO J 15: 2331.

Merlot S, Gosti F, Guerrier D, Vavasseur A, Giraudat J (2001) The $\mathrm{ABI} 1$ and $\mathrm{ABI} 2$ protein phosphatases $2 \mathrm{C}$ act in a negative feedback regulatory loop of the abscisic acid signalling pathway. Plant $J$ 25: 295-303. https://doi.org/10.1046/j.1365-313x.2001.00965.x.

Meyer K, Leube MP, Grill E (1994) A protein phosphatase 2C involved in ABA signal transduction in Arabidopsis thaliana. Science 264: 1452-1455. https://doi.org/10.1126/science.8197457.

Mori IC, Pinontoan R, Kawano T, Muto S (2001) Involvement of superoxide generation in salicylic acid-induced stomatal closure in $\mathrm{Vi}$ cia faba. Plant Cell Physiol 42: 1383-1388..

Nambara E, Marion-Poll A (2005) Abscisic acid biosynthesis and catabolism. Annu Rev Plant Biol 56: 165-185. https://doi.org/ 10.1146/annurev.arplant.56.032604.144046.

Nauš J, Rolencová M, Hlaváčkova V (2008) Is chloroplast movement in tobacco plants influenced systemically after local illumination or burning stress? Journal Integr Plant Biol 50: 1292-1299. https://doi. org/10.1111/j.1744-7909.2008.00743.x.

Oikawa K, Kasahara M, Kiyosue T, Kagawa T, Suetsugu N, Takahashi F, Kanegae T, Niwa Y, Kadota A, Wada M (2003) Chloroplast unusual positioning1 is essential for proper chloroplast positioning. Plant Cell 15: 2805-2815. https://doi.org/10.1105/tpc.016428.

Park SY, Fung P, Nishimura N, Jensen DR, Fujii H, Zhao Y (2009) Abscisic acid inhibits type 2C protein phosphatases via the PYR/ PYL family of START proteins. Science 324: 1068-1071. https://doi. org/10.1126/science.1173041. 
Pilot G, Lacombe B, Gaymard F, Cherel I, Boucherez J, Thibaud J-B, Sentenac H (2001) Guard cell inward K+ channel activity in Arabidopsis involves expression of the twin channel subunits KAT1 and KAT2. J Biol Chem 276: 3215-3221. https://doi.org/10.1074/jbc. M007303200.

Rock CD, Zeevaart JA (1991) The aba mutant of Arabidopsis thaliana is impaired in epoxy-carotenoid biosynthesis. Proc Natl Acad Sci USA 88: 7496-7499. https://doi.org/10.1073/pnas.88.17.7496 .

Rodriguez PL, Benning G, Grill E (1998) ABI2, a second protein phosphatase $2 \mathrm{C}$ involved in abscisic acid signal transduction in Arabidopsis. FEBS Lett, 421: 185-190. https://doi.org/ 10.1016/S00145793(97)01558-5.

Rojas-Pierce M, Whippo CW, Davis PA, Hangarter RP, and Springer PS (2014) PLASTID MOVEMENT IMPAIRED1 mediates ABA sensitivity during germination and implicates $\mathrm{ABA}$ in light-mediated chloroplast movements. Plant Physiol Biochem 83: 185-193. https:// doi.org/10.1016/j.plaphy.2014.07.014.

Rook F, Hadingham SA, Li Y, Bevan MW (2006) Sugar and ABA response pathways and the control of gene expression. Plant Cell Environ 29: 426-434. https://doi.org/10.1111/j.1365-3040.2005.01477.x.

Sakai T, Kagawa T, Kasahara M, Swartz TE, Christie JM, Briggs WR, Okada K (2001) Arabidopsis nph1 and npl1: blue light receptors that mediate both phototropism and chloroplast relocation. Proc Natl Acad Sci USA 98: 6969-6974. https://doi.org/10.1073/ pnas.101137598.

Sakamoto K, Briggs WR (2002) Cellular and subcellular localization of phototropin 1. Plant Cell 14: 1723-1735. https://doi.org/10.1105/ tpc.003293.

Senn G (1908) Die Gestalts- und Lageveranderung der Pflanzenchromatophoren. Leipzig Stuttgart: W. Engelmann (in German).

Shu K, Zhang H, Wang S, Chen M, Wu Y, Tang S, Xie Q (2013) ABI4 regulates primary seed dormancy by regulating the biogenesis of abscisic acid and gibberellins in Arabidopsis. PLOS Gen 9: e1003577. https://doi.org/10.1371/journal.pgen.1003577.

Sirichandra C, Wasilewska A, Vlad F, Valon C, Leung J (2009) The guard cell as a single-cell model towards understanding drought tolerance and abscisic acid action. J Exp Bot 60: 1439-1463. https:// doi.org/10.1093/jxb/ern340.

Suetsugu N, Kagawa T, Wada M (2005) An auxilin-like J-domain protein, JAC1, regulates phototropin-mediated chloroplast movement in Arabidopsis. Plant Physiol 139: 151-162. https://doi.org/10.1104/ pp.105.067371.

Suhita D, Kolla VA, Vavasseur A, Raghavendra AS (2003) Different signaling pathways involved during the suppression of stomatal opening by methyl jasmonate or abscisic acid. Plant Sci 164: 481488. https://doi.org/10.1016/S0168-9452(02)00432-6.

Sztatelman O, Waloszek A, Banaś AK, Gabryś H (2010) Photoprotective function of chloroplast avoidance movement: In vivo chlorophyll fluorescence study. J Plant Physiol 167: 709-716. https://doi. org/10.1016/j.jplph.2009.12.015.

Sztatelman O, Labuz J, Hermanowicz P, Banaś AK, Bażant A, Zgłobicki P, Aggarwal C, Nadzieja M, Krzeszowiec W, Strzałka W, Gabryś H (2016) Fine tuning chloroplast movements through physical interactions between phototropins. J Exp Bot. https://doi. org/10.1093/jxb/erw265.

Takagi S (2003) Actin-based photo-orientation movement of chloroplasts in plant cells. J Exp Biol 206: 1963-1969. https://doi.org/ 10.1242/jeb.00215.

Takemiya A, Shimazaki K (2010) Phosphatidic acid inhibits blue lightinduced stomatal opening via inhibition of protein phosphatase. Plant Physiol 153: 1555-1562. https://doi.org/ 10.1104/pp.110. 155689 .

Takemiya A, Sugiyama N, Fujimoto H, Tsutsumi T, Yamauchi S, Hiyama A, Tada Y, Christie JM, Shimazaki KI (2013). Phosphorylation of BLUS1 kinase by phototropins is a primary step in stomatal opening. Nature Commun 4: 2094. https://doi.org/ 10.1038/ncomms3094.
Tanaka Y, Sano T, Tamaoki M, Nakajima N, Kondo N, Hasezawa S (2005) Ethylene inhibits abscisic acid-induced stomatal closure in Arabidopsis. Plant Physiol 138: 2337-2343. https://doi.org/10.1104/ pp.105.063503

Tanaka Y, Sano T, Tamaoki M, Nakajima N, Kondo N, Hasezawa S (2006) Cytokinin and auxin inhibit abscisic acid-induced stomatal closure by enhancing ethylene production in Arabidopsis. J Exp Bot 57: 2259-2266. https://doi.org/10.1093/jxb/erj193.

Tlałka M, Runquist M, Fricker M (1999) Light perception and the role of the xanthophyll cycle in blue-light-dependent chloroplast movements in Lemna trisulca L. Plant J 20: 447-459. https://doi. org/10.1046/j.1365-313x.1999.00614.x.

Trojan A, Gabryś H (1996) Chloroplast distribution in Arabidopsis thaliana (L.) depends on light conditions during growth. Plant Physiol 111: 419-425. https://doi.org/10.1104/pp.111.2.419.

Tseng TS, Craig Whippo C, Hangarter RP, Briggsa WR (2012) The Role of a 14-3-3 Protein in stomatal opening mediated by PHOT2 in Arabidopsis. Plant Cell 24: 1114-1126. https://doi.org/10.1105/ tpc.111.092130.

Umezawa T, Sugiyama N, Mizoguchi M, Hayashi S, Myouga F, Yamaguchi-Shinozaki K, Ishihama Y, Hirayama T, Shinozaki K (2009) Type 2C protein phosphatases directly regulate abscisic acid-activated protein kinases in Arabidopsis. Proc Natl Acad Sci USA 106: 17588-17593. https://doi.org/10.1073/pnas.0907095106.

Umezawa T, Nakashima K, Miyakawa T, Kuromori T, Tanokura M, Shinozaki K, Yamaguchi-Shinozaki K (2010) Molecular basis of the core regulatory network in ABA responses: sensing, signaling and transport. Plant Cell Physiol 51: 1821-1839. https://doi.org/10.1093/ pcp/pcq156.

Verslues PE, Bray EA (2006) Role of abscisic acid (ABA) and Arabidopsis thaliana ABA-insensitive loci in low water potential-induced ABA and proline accumulation. J Exp Bot 57: 201-212. https://doi. org/10.1093/jxb/erj026.

Wada M, Kagawa T, Sato Y (2003) Chloroplast movement. Annu Rev Plant Biol 54: 455-468. https://doi.org/10.1146/annurev.arplant.54.031902.135023.

Wada M, Suetsugu N (2004) Plant organelle positioning. Curr Opin Plant Biol 7: 626-631. https://doi.org/10.1016/j.pbi.2004.09.005.

Walczak T, Gabryś H (1980) New type of photometer for measurements of transmission changes corresponding to chloroplast movements in leaves. Photosynth 14: 65-72. .

Walker-Simmons MK, Abrams SR (1991) Use of ABA immunoassays. In Abscisic acid physiology and biochemistry. Davies WJ, Jones HG eds, pp 53-63. Oxford: Bios Scientific Publishers. .

Wang XL, Gao XQ, Wang XC (2011) Stochastic dynamics of actin filaments in guard cells regulating chloroplast localization during stomatal movement. Plant Cell Environ 34: 1248-1257. https://doi. org/10.1111/j.1365-3040.2011.02325.x.

Wind JJ, Peviani A, Snel B, Hanson J, Smeekens SC (2013) ABI4: versatile activator and repressor. Trends Plant Sci 18: 125-132. https:// doi.org/10.1016/j.tplants.2012.10.004.

Yamburenko MV, Zubo YO, Börner T (2015) Abscisic acid affects transcription of chloroplast genes via protein phosphatase $2 \mathrm{C}$-dependent activation of nuclear genes: repression by guanosine-3'-5'bisdiphosphate and activation by sigma factor 5. Plant J 82: 10301041. https://doi.org/10.1111/tpj.12876.

Zhang Z, Feng L-Y, Cheng J, Tang H, Xu F, Zhu F, Zhao ZY, Yuan M, Chen Y-E, Wang J-H, Yuan S, Lin H-H (2013) The roles of two transcription factors, ABI4 and CBFA, in ABA and plastid signalling and stress response. Plant Mol Biol 83: 445-458. https://doi. org/10.1007/s11103-013-0102-8 .

Zhang X, Wang H, Takemiya A, Song C, Kinoshita T, Shimazaki K (2004) Inhibition of blue light-dependent $\mathrm{H}+$ pumping by abscisic acid through hydrogen peroxide-induced dephosphorylation of the plasma membrane H+-ATPase in guard cell protoplasts. Plant Physiology 136: 4150-4158. https://doi.org/10.1104/pp.104.046573

Zurzycki J (1955) Chloroplast arrangement as a factor in photosynthesis. Acta Soc Bot Pol 24: 27-63. 